\begin{tabular}{|c|c|}
\hline 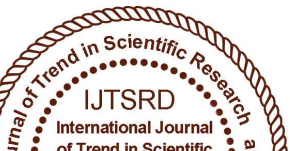 & $\begin{array}{l}\text { International Journal of Trend in Scientific } \\
\text { Research and Development (IJTSRD) }\end{array}$ \\
\hline 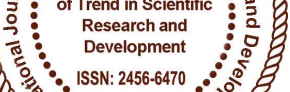 & International Open Access Journal \\
\hline 000 & ISSN No: 2456 - 6470 | www.ijtsrd.com | Volume - 2 | Issue -4 \\
\hline
\end{tabular}

\title{
A Study of Generation of Food Waste and Awareness Regarding the Food Waste Amongst Indian Households
}

\author{
Dr. Kalyani Srinivas $C^{1}$, Ms. Rina Dongre ${ }^{2}$ \\ ${ }^{1}$ Professor, ${ }^{2}$ Assistant Professor \\ ${ }^{1}$ Modern College of Engineering, ${ }^{2}$ AISSMS College of Hotel Management \& Catering Technology \\ ${ }^{1,2}$ Pune, Maharashtra, India
}

\section{ABSTRACT}

"The food is available in abundance and is affordable". This misconception has led to tremendous food waste which is as severe as $50 \%$. Therefore, one should not undermine the importance of controlling food waste which will give way to food security. "To have access to the wholesome food"which is the basic human right of each individual, will be achieved if we can control the food waste.

This study is aimed at analysing the reasons of generation of food waste in Indian households and the degree of awareness regarding the negative impacts of food waste amongst them. In an effort to do so, a sample survey in the form of questionnaire was conducted from the adult individuals to understand their views on the topic.

The findings of this research states that majority of the perishable food waste is generated because of the bulk purchases or if the preparation is not liked by the family members. The practice of reusing the leftovers either in the same form or making a new dish using the leftovers is prevalent in Indian households. Expiry is not a significant reason of wastage. Individuals seemed to be very well aware about the environmental and economic impacts of food waste.

Keywords: Food Waste, Food Waste Management, Food Security, Food Loss, Leftovers

\section{INTRODUCTION}

\section{Food Waste:}

Food waste is defined as discarding raw or cooked food material at any stage of the supply chain and consumption.

Therefore, the waste generated before, during and after food preparation in the households, restaurants, farms, retailers and food manufacturing company is included in food waste.

Food waste can be divided into two categoriesavoidable and unavoidable. Avoidable food waste is edible prior to disposal whereas unavoidable waste consists of egg shells, peels, seeds, bones etc. which is not edible under normal circumstances. In this paper, only avoidable waste has been considered and discussed.

A serious concern in a large part of the developing world is that of food security. A significant increase in food production is a necessity in order to meet the future demands of the ever-expanding world population. At the same time, controlling the waste at various stages of production, so as to make the food accessible and affordable for everybody, is equally important. As per FAO, 2014 report, better management of food supply chain and avoiding the food waste is one of the promising option for reducing global hunger

This study stresses upon the factors generating food waste amongst the Indian households and the level of awareness regarding the impact of food waste. Multiple studies have concluded that households are major contributors to food waste. Hence, it is important to identify the patterns of food waste in households and spread the awareness about its negative impact. 
This study is an attempt to find out the consumption patterns and thereby wastage patterns amongst the Indian households.

\section{LITERATURE REVIEW}

1. Federica Marra (2013) in her study has claimed that food losses and waste has got worldwide attention in recent years because of its direct role in threatening environmental, social and economic sustainability. The study points to the generic decrease in food availability due to sub-par functioning of food systems and food value chains. She further stated that because of globalization, the food wasted in one part of the world affects the availability and prices elsewhere, thus making the consequences of food waste and losses global.

2. Rutten.M et al (2013), in the report, have categorized the occurrence of food wastage in 5 categories- a) Agriculture, hunting and forestry, b) Manufacturing, c) Wholesale \& retail, d) Foodservice and catering, and e) households. It's been mentioned there that maximum food wastage occurs in households i.e. $30.9 \%$

3. Monier et.al (2012), in his study has mentioned that in EU, out of total food wastage, $42 \%$ is contributed by households, $39 \%$ by the manufacturing industry and $19 \%$ by other sectors.

4. Lundqvist et.al (2008) in the study has identified food waste as a cause of global concern that affects the society, the environment as well as the economy adversely. In Europe, approximately one third, of the food produced for human consumption is wasted every year. He has listed increase in population, changing dietary preferences, urbanization, global warming as some of the reasons for increase in global food waste.

5. Beaver $M$ in his study has claimed that $60 \%$ of the household waste in UK comprises of the food which is not used in time. Perishable products are the major contributors towards the food waste. He claims that behaviors and attitude of customers regarding the packaging is the major barrier to reduce the food waste. Customers are ill-educated regarding the benefits of existing packaging and they don't read and understand the instructions carefully.

6. Lazaros \& Shackelford (2008) have mentioned in their study that household contributes to around $70 \%$ of the total food wastes internationally. The residents purchase the food and do not consume. Edible food is many times thrown in the dustbin. They pointed that volume of the food waste increases with the rise in disposable income.

7. Wolfgang et.al (2014) in his study has pointed out that in the households generate waste based on preferences for a certain level of quality of food items. Some parts of food items are discarded purely out of preference, for e.g. peeling of potatoes, fish heads/tails, chicken skin, etc. Food items are stored for a certain duration and then simply thrown away without utilizing. Such type of food wastage can be avoided by changing the preferences to some extent.

Waste also depends upon the storage times at household level: some food may not be considered palatable after a while and is disposed. This can be avoided by increasing shopping frequency so as to reduce storage duration. Food waste might also be avoided by spending more time on food preparation, e.g. to peel fruits and vegetables more carefully, or to prepare dishes from not completely fresh products (e.g. to use stale vegetable preparation for making stuffed paratha (Indian bread), using stale roti( Indian Bread) to make khakra (dried Indian bread eaten as snacks).

8. HKIED (2011) has claimed in its study that Consumerism promotes the excessive purchasing of food products without the consideration of negative environmental impacts. He says that consumerist lifestyle, which manifests in buying excessive food stuff which ultimately is disposed. It created significant environmental problems to Hong Kong.

9. Macy .J, (2002) in her study pointed out that unsuccessful food waste source reduction is because of indifferent attitude regarding the environment. Customers buys excessive food, don't plan for the purchase, to avail bulk purchase discounts ,often buy more than required, storing equipment not functioning properly, improper storage of food, improper serving sizes, and leftovers not being used are some of the 
indifferent attitudes which contributes towards wastage.

10. Yang, et al (2011) has claimed in the study that since the facilities for proper recycling are not available, it promotes the food waste generation in households. Proper sorting of garbage in households and socially responsible behavior is required for waste reduction.

11. WRAP (2008) claims that, in the United Kingdom (UK), one third of food products purchased by household ends up in the waste bin. Of the total wasted food, a staggering $61 \%$ or about $70 \mathrm{~kg}$ per household can actually be avoided. $40 \%$ isn't even touched and at least $10 \%$ is wasted while within its expiry period. About $45 \%$ of the food thrown away in the UK by weight consists of salad items. The main identified reasons for throwing away edible food by WRAP are plate leftovers, expiration date passed, aesthetic appearance, moldiness and cooking leftovers. Lack of awareness, oversized portions and consumer attitude are some of the other reasons mentioned for food wastage.

\section{OBJECTIVES OF THE STUDY}

1. To study out the reasons for food waste in Indian Households.

2. To find out the amount of food wasted in Indian households.

3. To analyze the level of awareness amongst the Indian households regarding the impacts of food waste.

\section{LIMITATIONS OF THE STUDY}

1. The study is based on responses received by those who have access to smart phones/internet. A total of 123 responses were received.

2. This study is conducted in current scenario. The perceptions, opinions and behavior of the respondents might change with time.

\section{RESEARCH METHODOLOGY}

\section{Type of Research}

This study is based on food waste generated in households during day today life and does not include feasts or festival days and included following methods of data collection. The feasts or festival days are the special occasions where lot of other factors are responsible for food waste, which can be a scope for further research.

\section{Methods of Data Collection}

Primary data: It was collected with the help of questionnaire technique. A structured questionnaire was prepared and the responses are collected through Social communication networks, further it was tabulated using Google docs software

Secondary data: It was collected from published literature on food waste management, latest references available from the journals, newspapers, research publications and magazines, and other relevant sources like internet.

\section{DISCUSSIONS, FINDINGS \& CONCLUSIONS}

\subsection{Discussions}

\subsubsection{Reasons for non-consumption of food}

As per the findings, the major reason for the non-consumption of the food in the houses is overcooking followed by last minute outing and changes in the meal plans. Another major reason is the taste not liked by the family members

\subsubsection{Amount of food wasted:}

A majority that is $79.8 \%$ has claimed that they waste less than $5 \%$ of the food in their houses. $18.5 \%$ have agreed that they waste the food between $5-10 \%$ in their houses while $1.7 \%$ of the respondent has agreed that they waste between $10-20 \%$ of the food. None of the respondents have reported a wastage exceeding $20 \%$.

\subsubsection{Impacts of food waste:}

A majority that is $83.1 \%$ of the respondents are aware that food waste has social, economic as well as environmental impacts.

\subsubsection{Awareness about the food waste:}

Creating awareness amongst the general public regarding the direct and indirect repercussions of food waste on the economy, environment and the society is one of the most important tool to reduce the food waste. Greater the awareness, more innovative method would be adopted by the public to 
International Journal of Trend in Scientific Research and Development (IJTSRD) ISSN: 2456-6470

reduce the food waste. Majority of the respondents strongly agree that controlling food waste has nothing to do with the affordability and $79.8 \%$ of the respondents claim that the amount of the food wastage is not more than $5 \%$ at their homes. $83.1 \%$ of the

respondents are aware that food waste has social, economic and environmental impacts. A miniscule $0.8 \%$ of the respondents disagree with the notion of avoiding food waste even if one can afford to.

\subsection{Findings}

What do you think are the reasons for non consumption/leftovers? (109 responses)

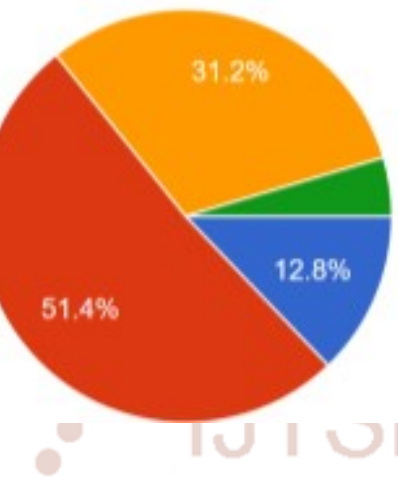

Taste not liked by family members

Excess quantity of cooked food

Last minute outing or change in plan

Other

What do you think are the impacts of food waste? (118 responses)

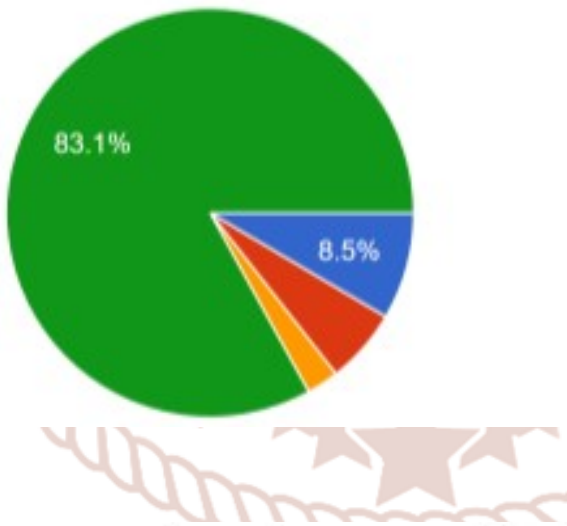

Social ( could have been consumed by someone else)

Economical

Environmental

All three

Do you agree that even though you can afford,you should avoid food waste? (120 responses)

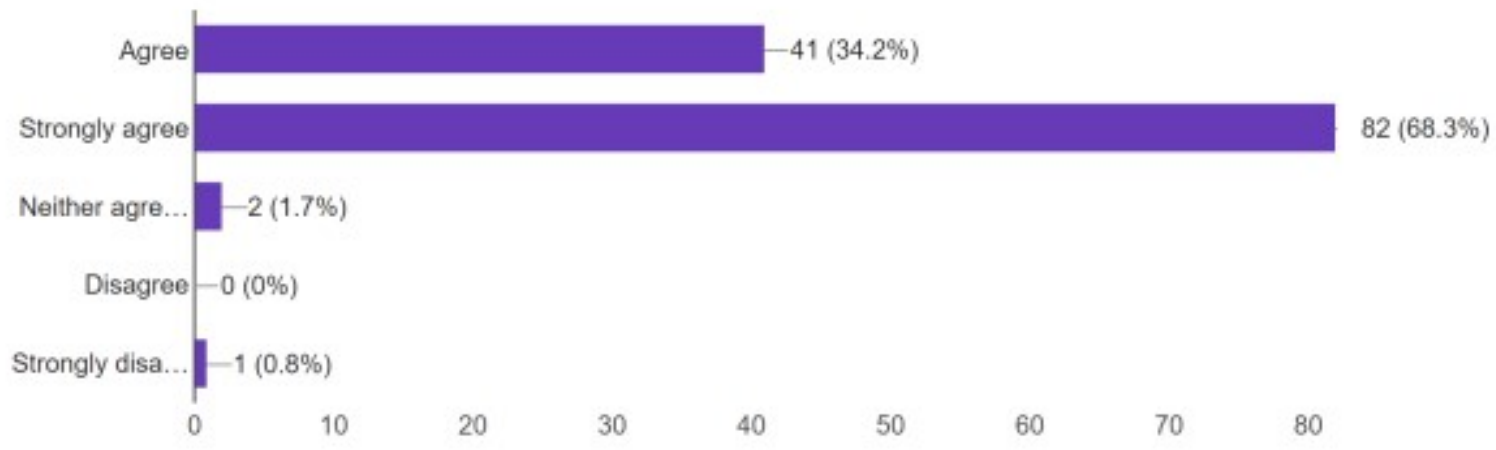




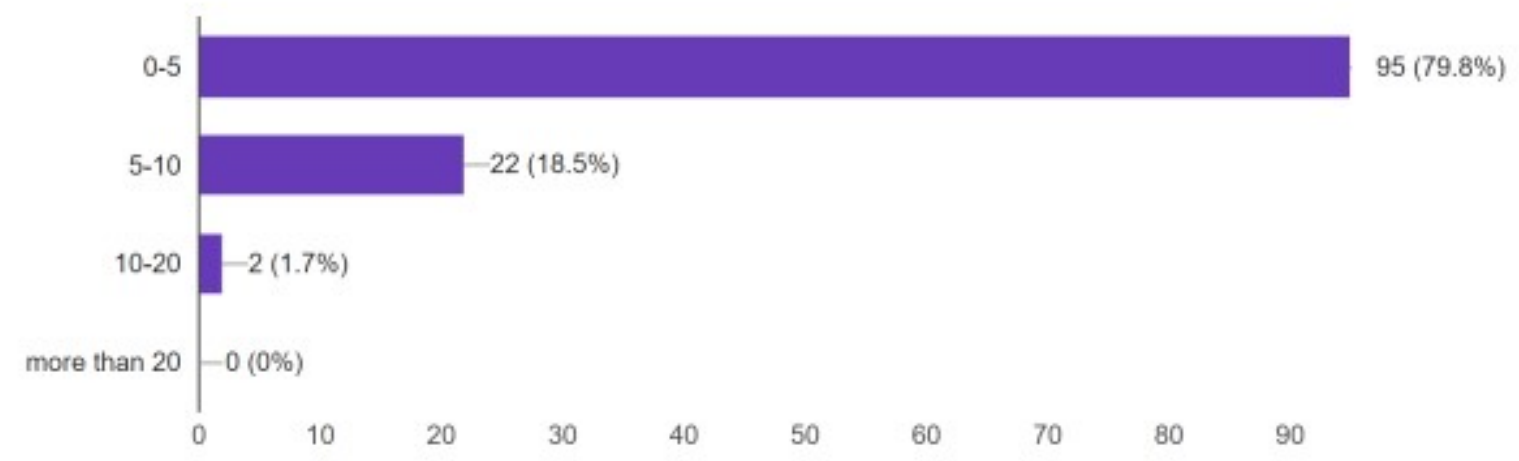

\subsection{Conclusions}

In Indian culture, food is considered to be sacred. Being a developing nation, the amount of food wasted in India is comparatively less as compared to other developed countries. However, the rise in disposable income and easy accessibility to the food is gradually giving rise to food waste in India. Excess quantity of food cooked is the major reason for the food wastage.

Overall, the householders claim to be aware about the repercussions of food waste and strongly agree that food should not be wasted.

\section{SUGGESTIONS \& RECOMMENDATIONS}

Based on the responses received following suggestions can be made:

- Cooking as per the requirements

- Reusing the leftovers.

- Better house hold planning which means checking the stock at home before shopping.

\section{BIBILIOGRAPHY}

1) Federicca Marra, Fighting Food Loss and Food Waste in Japan. (2013)

2) Rutten, M.M., Nowicki, P. L., Bogaardt, M.J. and Aramyan L. H. (2013) 'Reducing food waste by households and in retail in the EU; A prioritization using economic, land use and food security impacts', LEI Report 2013-035, The Hague: LEI, part of Wageningen UR

3) Monier, V., Shailendra, M., Escalon V., O'Connor, C. Gibon, T. Anderson, G. Hortense, M. Reisinger, H. 2010. Preparatory study on Food Waste across EU27. European Commission (DG ENV) Directorate C- Industry. 2010. Final Report.
ISBN: 978-92-79-22138-5. Evans, D. (2012). 'Beyond the throwaway society: ordinary domestic practice and a sociological approach to household food waste sociology, 46(2012)

4) Lundqvist, J., De Fraiture, C. \& Molden, D. (2008) Saving Water: From Field to ForkCurbing Losses and Wastage in the Food Chain. SIWI policy Brief. Stockholm: SIWI

5) Matthew Beaver- Managing Food Wastage in the Consumer Household

6) Lazaros, Edward J, \& Shackelford, Ray. (2008). Don't Throw It Away! Raise Recycling Awareness Through Communications Project. Tech Directions, 67(6), 19-23

7) Wolfgang, B., Hasan, D., Ferrari, E. (2014) Economy-wide Impacts of food waste reduction: A general Equilibrium Approach. Wolfgang Britz, Hasan Dadu, Emanuele Ferrari

8) HKIED, \& CSD. (2011). Sustainable development in Hong Kong: Concepts, contexts and challenges by Hong Kong institute of Education and Council for sustainable Development.

9) Macy, Jack. (2002). Food residuals put city on track to over 50 percent diversion. Biocycle, 43(2), 40-46

10) Yang, Lei, Li, Zhen-Shan, \& Fu, Hui-Zhen. (2011). Model of Municipal Solid Waste Source Separation Activity: A case Study of Beijing. Journal of the Air \& Waste Management Association, 61(2), 157-163

11) WRAP (2008): Research into Consumer Behavior in Relation to Food Dates \& Portion Sizes. Report prepared by WRAP, Barbury 